\title{
EL MENSAJE COMPROMETIDO ES OTRA PUBLICIDAD
}

Magdalena Mut-Camacho': Universitat Jaume I. España magda.mut@com.uji.es

Estela Bernad-Monferrer: Universitat Jaume I. España bernad@com.uji.es

\section{RESUMEN}

El presente trabajo pretende analizar los tipos de mensajes publicitarios que utilizan mensajes sociales, para así dilucidar si la responsabilidad social corporativa es posible situarla en el marco conceptual de la nueva forma de entender el mensaje empresarial bajo la mirada de la RSC. Se pretende aportar conocimiento y desarrollo de un estudio constructivo, que pueda servir para buscar las bases conceptuales y metodológicas para la elaboración y compresión de esta área de la gestión empresarial moderna donde la comunicación supone una estrategia importante, donde el mensaje corporativo que se lanza, entendiéndolo como una forma de colaboración en la construcción social, propicia el desarrollo de una sociedad que avanza con valores.

PALABRAS ClAVE: Publicidad - Comunicación - Responsabilidad Social Estrategia

\footnotetext{
${ }^{1}$ Autor correspondiente

Magdalena Mut-Camacho: Profesora. Universitat Jaume I. Castellón de la Plana (España).

Correo: magda.mut@com.uii.es
} 


\title{
ENGAGEMENT ADVERTISING, ANOTHER MESSAGE
}

\begin{abstract}
The role of the company has transformations. Social demands have been the cause of these mutations because society requires responsibility and transparency. Some companies decide to incorporate into their communication strategy as a way to report to the society, becoming the best presentation: its social, ethical and environmental issues. This strategy consistent and maintained over time provides intangible benefits that increase the value of the organization. Today the trust has become a core value in all organizations, but the value bet on this core value to appear before identifying stakeholders is a strategy that addressed with great originality and neatness some companies. This article aims to analyze the types of advertisements that use social messages, thereby determine whether corporate social responsibility can place it in the framework of the new way of understanding the business message.
\end{abstract}

KEY WORDS: Advertising - Communication - Social Responsibilitiy - Strategy

\section{INTRODUCCIÓN}

En la actualidad al hablar sobre «comunicación», por un lado, nos situamos ante una serie de conocimientos y habilidades que manejados con talento e intuición, sirven para producir comunicación competitiva, relaciones eficaces, duraderas y sólidas que puede servir de base al progreso empresarial, la sostenibilidad y el bienestar social. Por otro lado, nos hallamos ante unas organizaciones con necesidad de conocer los métodos y modos de comunicación para continuar en el complicado mundo real, progresar y no acabar relegados en la mera supervivencia, el retraso y la falta de competitividad.

El papel de la empresa ha sufrido profundas transformaciones a lo largo de la historia, y probablemente ahora nos hallamos en un momento de cambio aún por concluir. Las demandas sociales han sido, entre otras, causantes de estas mutaciones pues la sociedad le exige a las empresas ante todo responsabilidad y transparencia. Esta forma de actuar de las empresas no tan sólo ha sido integrada en el ser de la organización y ha pasado a formar parte de su identidad corporativa, sino que además, algunas empresas deciden incorporarlas a su estrategia de comunicación como forma de presentarse ante la sociedad, convirtiéndose en su mejor carta de presentación: su compromiso social, ético y medioambiental. Esta estrategia firme, coherente y mantenida en el tiempo aporta beneficios intangibles que aumentan el valor de la organización. 
Hoy en día la confianza se ha convertido en un valor esencial en todas las organizaciones, pero el apostar por este valor como principal valor identificativo para presentarte ante los stakeholders es una estrategia que abordan con gran originalidad y pulcritud algunas empresas. El presente trabajo pretende analizar los tipos de mensajes publicitarios que utilizan mensajes sociales, para así dilucidar si la publicidad comprometida es posible situarla en el marco conceptual de la nueva forma de entender el mensaje empresarial bajo la mirada de la sociedad.

Se pretende aportar conocimiento y desarrollo de un estudio constructivo que pueda servir para buscar las bases conceptuales y metodológicas para la elaboración y compresión de esta área de la gestión empresarial moderna donde la comunicación supone una estrategia importante, donde el mensaje corporativo que se lanza, entendiéndolo como una forma de colaboración en la construcción social, propicia el desarrollo de una sociedad que avanza con valores.

\section{METODOLOGÍA}

El objetivo del presente artículo es extraer conclusiones sobre cómo la publicidad unida a intención de mostrar los valores sociales de la organización, es utilizada en la estrategia comunicativa de la empresa con gran efectividad y éxito creativo. Para ello se a realizar un repaso a diferentes campañas publicitarias como ejemplo de empresas que apuesta en su comunicación por mostrar un mensaje socialmente comprometido vinculado a su producto/servicio, como nexo de unión con la sociedad y adaptación al entorno.

Por lo tanto, partimos de la hipótesis de que las empresas deben contemplar su identidad corporativa en sus estrategias de comunicación, como parte integrante de su desarrollo, para un correcto avanzar en consonancia con el entorno y la sociedad en la que están involucradas.

Para llevar a cabo esta investigación se propone el análisis de textos relacionados con la temática en cuestión para posteriormente aplicarlos de manera práctica a la comunicación de los ejemplos seleccionados.

\section{ANÁLISIS Y DISCUSIÓN}

\subsection{La empresa de hoy cree en su lado intangible}

Un buen comienzo es comprender que la empresa de hoy en día y de futuro es aquella que entiende la existencia de una nueva sensibilidad en su seno, en consonancia con la nueva sensibilidad que demanda la sociedad en continua evolución y exigencia. 
Esa racionalidad empresarial renovada se caracteriza para un número creciente de compañías por la asunción de la ética y la sostenibilidad como dos principios básicos de la gestión. En el momento en el que aparecen lógicas diversas dentro del mundo empresarial, no sólo la del retorno de la inversión y la maximización del beneficio, sino también la del retorno para otros stakeholders, aumenta la pertinencia del diálogo con estos grupos y ese diálogo y las nuevas habilidades de relación de la empresa elevan también su valor intangible (Villafañe, 2004, p.242).

La empresa demuestra ser un sistema dinámico, esto es así porque tiene múltiples actores que se comunican, se coordinan para conseguir objetivos, se intercambian información, interactúan unos con otros y se influyen mutuamente. Las acciones de unos, influyen sobre las que otros iniciarán más tarde y así constantemente. Es por eso que se decide centrar la fundamentación teórica de esta investigación sobre la empresa, sobre cómo la imagen corporativa pasa a formar parte de su gestión estratégica, cómo esta gestión va tomando relevancia igualándose a otras gestiones y cómo la gestión de la comunicación corporativa alcanzará un estadio de máximo desarrollo pasando a ser la gestora de los intangibles de la empresa.

En esta evolución hacia una cultura de la imagen corporativa, lo que Costa denomina un camino hacia la "mentalidad corporatista" (Costa, 2001, p.123), influirán factores decisivos en el progreso de la organización como es el estar regida por unos valores. Estos valores son mucho más que códigos formales y declaraciones. Hay pues, como resultado de estas evoluciones, una transformación multipolar que va de la cultura de la producción a la cultura de la comunicación y de la información.

Va también de una relación espontánea dentro de la empresa, a una interacción técnica y estructurada. Se descubrirá una proyección vertida hacia el mercado y el cliente (en la vertiente comercial), y hacia la sociedad y el individuo (en la vertiente institucional). Vemos también el paso de la publicidad de productos y marcas a la comunicación de intangibles. De la mentalidad mecánica del industrialismo a la mentalidad telemática. Del producir al servir. De lo que hoy nos parece una publicidad sin más, a la comunicación convertida en elemento estratégico y herramienta de acción.

Por otra parte, en esta evolución hacia una cultura de lo intangible también influirán transformaciones externas: la evolución de una sociedad que va mutando sus valores. Estos valores sociales, si bien se localizan en esta etapa contemporánea, también son el fruto de evoluciones precedentes, sedimentadas las más antiguas en las más recientes, y que facilitan en conjunto una compresión de las ideas que se han ido sucediendo, así como de las técnicas y los valores que las han acompañado. 
Aquel primer modelo de empresa del industrialismo, cimentado en la coyuntura y creencias del siglo XIX, cuyos pilares inamovibles eran capital, organización, producción y administración, fue reinventándose. Este modelo fundador hoy ha desaparecido detrás de las cortinas de la estrategia.

La comunicación humana en su componente sociológico en la empresa y la comunicación relacional, que paradójicamente están en la naturaleza misma de la organización, empiezan a penetrar en ella a través de nuevos conceptos e instrumentos operacionales: la noción de identidad, la cultura organizacional, la comunicación interna, la integración de las comunicaciones, los programas de calidad, la gestión del conocimiento.

Desde las lejanas perspectivas en las que se forjó la invención de la empresa, ha ido evolucionando la mentalidad y la actividad empresarial en el decurso del tiempo. En cada fase evolutiva han emergido nuevas necesidades estratégicas y de acción que han obligado a la empresa a reinventarse.

A través del tiempo y de todas estas evoluciones aparecieron en las empresas nuevos actores, nuevas situaciones, nuevas técnicas que había que gestionar: los recursos humanos, la cultura organizacional, la formación permanente, los programas de calidad, la cultura de servicios, la integración de las comunicaciones, la identidad corporativa o la diferenciación como factor competitivo, la microsegmentación de los públicos.

La empresa actual ha nivelado la importancia de sus tangibles y de sus intangibles. De gestionar con notable excelencia todos los vectores estratégicos que llevó la industrialización, como producto, precio, distribución, administración, producción, etc. ha pasado a gestionar unos nuevos vectores intangibles.

Esta progresiva y convergente desmaterialización del entorno de la empresa la ha llevado a la consideración de lo material desde un ángulo nuevo. En esta nueva dimensión de la empresa que se abre, la organización hace valer su identidad, a través de los productos o servicios que presta, a través de las personas que lo prestan, a través de sus maneras de hacer las cosas y a través de su comunicación. Hoy en día, los productos y servicios se hallan en el rasero de la igualación, por tanto, se hace necesaria la estrategia de la diferenciación. La comunicación se convierte en un importante elemento diferenciador poderoso y estratégico.

Hoy en día, los fenómenos de opinión se han convertido en uno de los motores más dinámicos del devenir del mercado: la ideología ingresa en el mercado como mercancía y el estado de opinión es un bien capital. Todo esto lleva a constatar que es la identidad corporativa, la reputación corporativa y la comunicación corporativa son las na1tas aue marca el desarrollo económico de una organización aue se crea 


\subsection{La intención, una nueva dimensión social en la publicidad}

Comprobamos como hubo un momento en la historia de las empresas, un momento próximo en el tiempo, en el que se pasó de un plano puramente táctico de las comunicaciones hacia un escenario necesariamente estratégico (situación actual). Las estructuras se modifican para mejorar los estándares de competitividad en una sociedad cada vez más exigente y personalizada en su comunicación, con exigencias y expectativas que proyectan y anhelan cumplan las empresas y organizaciones.

Hoy en día, asistimos a los vaivenes sociales, económicos y políticos, e inserto en ellos está el consumo de información, que ha crecido de modo estrepitoso, afectando con cambios notables las conductas de los individuos y públicos de la empresa, quienes parecen evolucionar generacionalmente hacia una nueva forma de entender del consumo comunicacional.

La sociedad va variando sus modelos y la realidad empresarial también debe ir dando cabida a nuevos valores. La séptima edición del Trust Barometer, elaborado por el Grupo Edelman, recogió las impresiones de líderes de opinión de 11 países y fue presentado en el Foro Económico Mundial de Davos 2006, el estudio destacó la aparición de una figura que en los últimos años ha ganado credibilidad, se trata de la figura del «interlocutor cercano» con el que el receptor de la información se puede identificar fácilmente, es decir, alguien que responde al concepto de «una persona como yo».

Estas y otras variables tienden a demostrar que la configuración de las sociedades modernas no permite que únicamente sean los modelos tradicionales de comunicación en la empresa los tengan espacio para soluciones exitosas. Ahora cabe la posibilidad de afrontar el mensaje publicitario de una forma además de creativa, comprometida.

Las empresas, en esa redefinición de su papel en el mundo, en esa asunción de nuevas responsabilidades ante la sociedad, sociedad de la que dependen y en la que viven, no sólo actúan sino que también informan sobre cómo actúan y también sobre cómo piensan. Pero incluso más, sobre cómo piensan y cómo pueden ayudar a cambiar las cosas, con la implicación de toda la sociedad.

Comprobamos como esta empresa concienciada, mantiene informado de su compromiso a su público, pero también decide emprender nuevas acciones de comunicación/concienciación, donde el público al que van dirigidos su mensajes es el público ciudadano, ya sea consumidor o no. Buscando ser ese interlocutor cercano y preocupado como todos. 
Una forma de acceder al público es la publicidad, a través de un mensaje que puede parecer incómodo pero que es altamente comprometido, pues esta publicidad además de su objetivo comercial ofrece «algo más» en beneficio de todos. De forma que, descubrimos un nuevo mensaje que además de presentar el producto/servicio fomenta valores sociales o invita a la reflexión de valores sociales, contribuyendo así la mejora de la sociedad y propiciando el desarrollo de una comunidad socialmente avanzada. Esto lo consigue siendo ella comprometida socialmente y siendo innovadora, pues reinventa su discurso en beneficio de todos; siendo justa y solidaria, pues fomenta valores que la sociedad demanda sean fomentados desde todos los ángulos.

Ese camino lo inició el fotógrafo Oliviero Toscani en sus dieciocho años de relación con Benetton, cuando inaugurados los años 90 reinventó la publicidad. Contra todo construyó su publicidad con una intención comprometida más allá de presentar al producto, y asoció a la marca el compromiso social y la reflexión. Toscani fue un transgresor en su forma de presentar el mensaje, pero lo importante fue la valiente apuesta de una compañía que construyó su identidad corporativa creyendo que el ser humano surge si se le da una oportunidad y así lo anunció a los cuatro vientos. En la actualidad sigue manifestándose con una optimista y original propuesta.
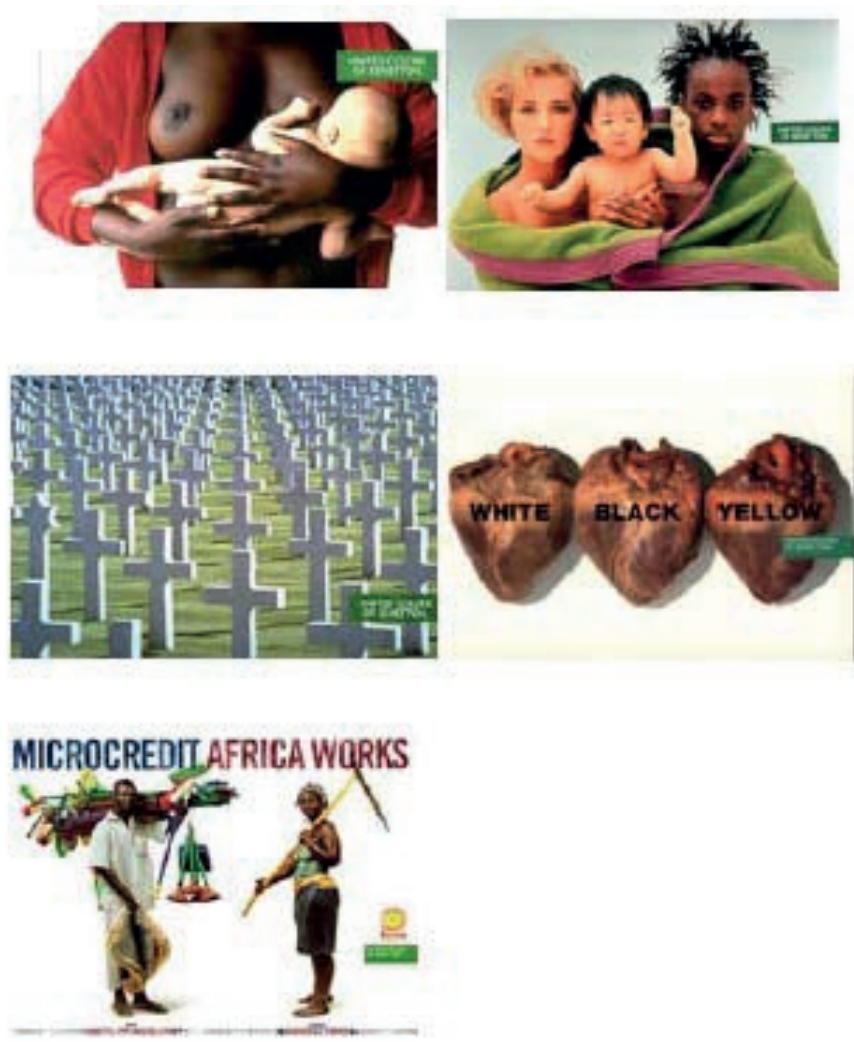

Figura 1. Cuatro vientos 
En el año 2007 Toscani volvió a escandalizar cuando realizó la campaña para la empresa de moda italiana Nolita, advirtiendo de los perjuicios de la anorexia.

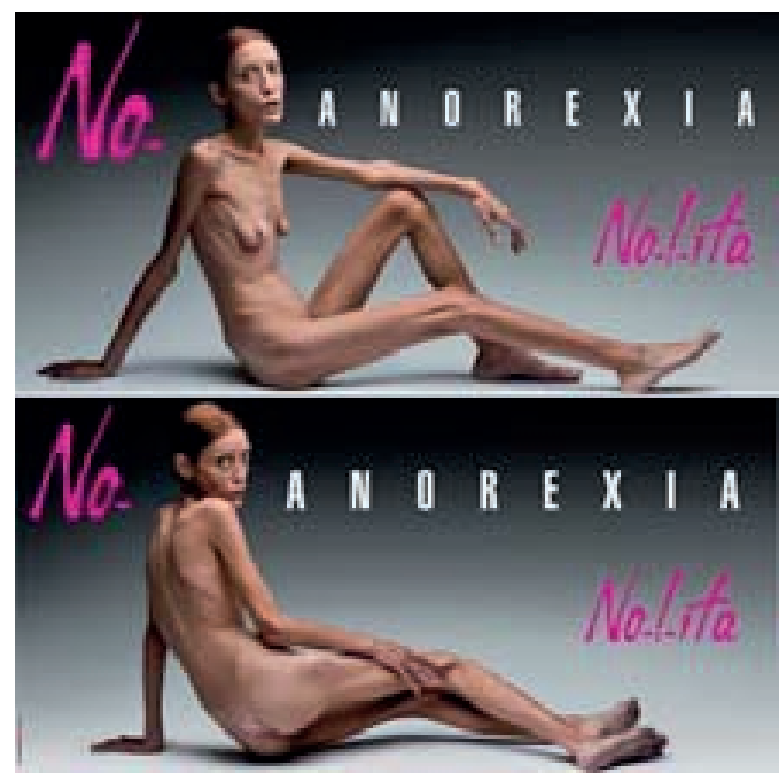

Figura 2. Moda italiana Nolita

En la actualidad comprobamos como muchas empresas deciden integrar en sus mensajes publicitarios ese «algo más». Esta intención añadida redunda en la concepción de un mensaje donde además de estar presentando su producto o servicio se está mostrando a ella misma como empresa comprometida cuando ese «algo» sirve para meditar.

La empresa Debenhams, unos grandes almacenes británicos, realizó una publicidad en la que incluían modelos fuera de lo común, con más talla de lo habitual y con más y menos altura de lo habitual, además de incluir a una discapacitada. Inteligente forma de hacer reflexionar sobre los diferentes modelos físicos normales y habituales que la sociedad tiene. 


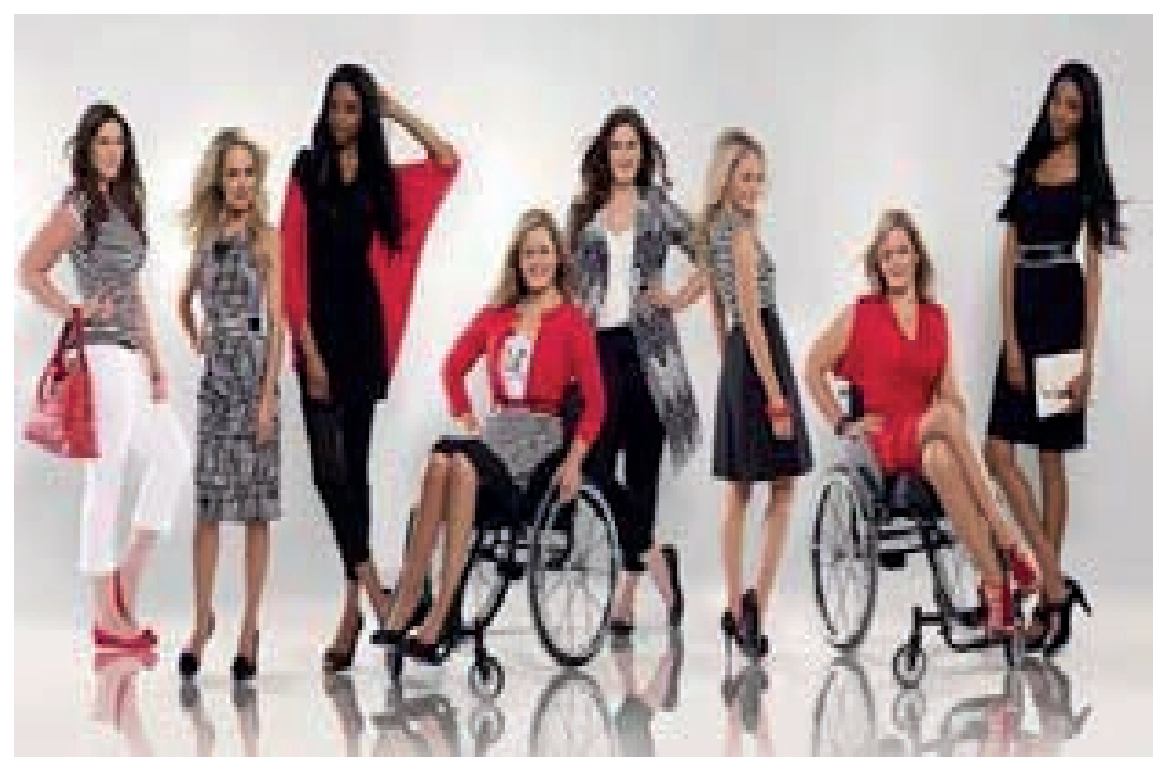

Figura 3. Campaña de publicidad de la marca de moda Diesel

Otra forma original de ofrecer ese «algo más» en beneficio de la sociedad lo hallamos también de forma original y magistral en la campaña de publicidad de la marca de moda Diesel. La marca coloca a sus modelos en escenarios irreales con el objetivo de llamar la atención sobre una cuestión en la que se sienten comprometidos como miembro de la sociedad, así que aprovecha la oportunidad que tiene como empresa.

Una estrategia donde su gráfica es una denuncia, además de una presentación de su producto. Se completa desde su Web, desde donde invita a adherirse a la lucha contra el calentamiento global.

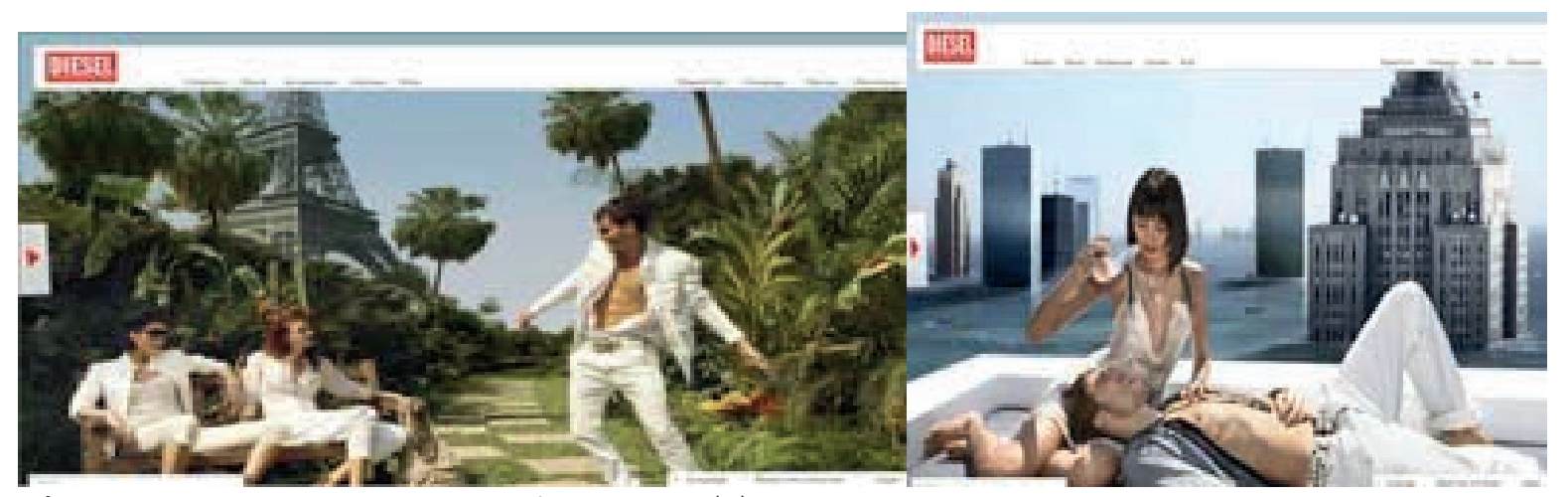

Figura 4. La campaña Re_Accionav (1) 


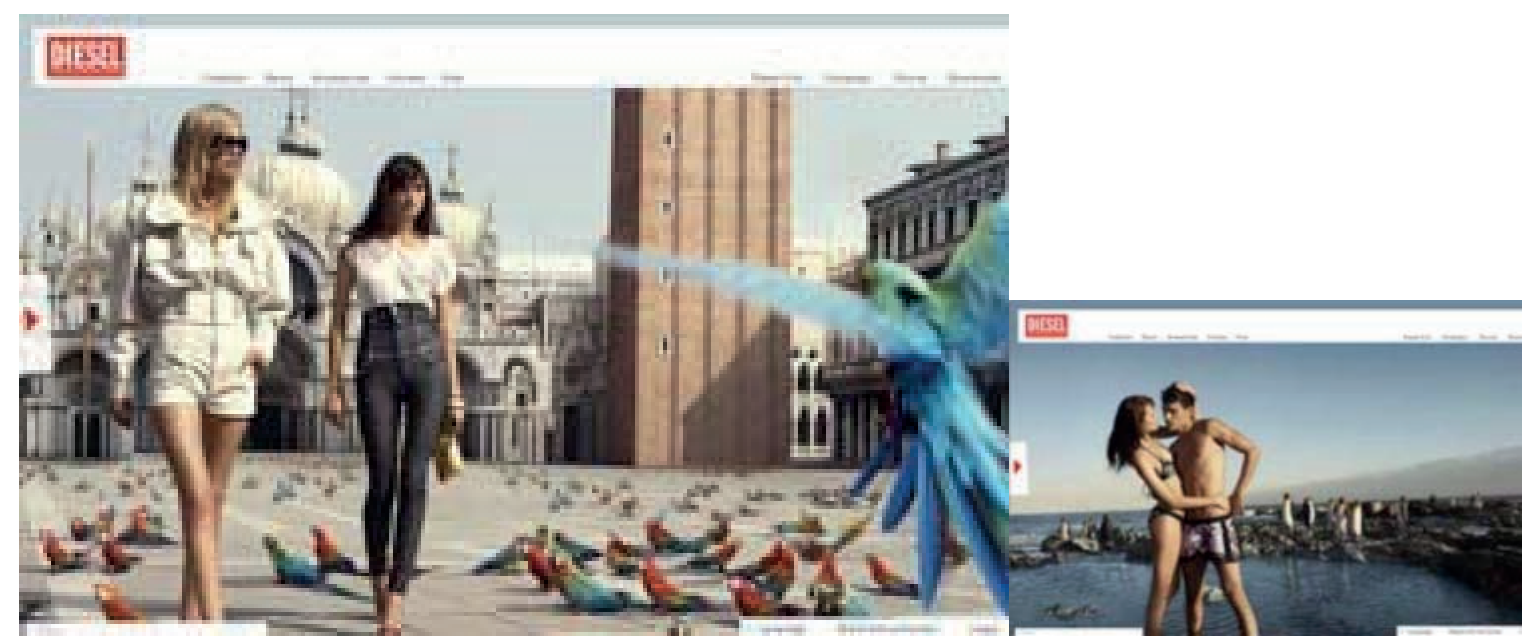

Figura 5. La campaña Re_Accionav (3)

La empresa Acciona en coherencia con su filosofía corporativa en 2009 pone en marcha una campaña publicitaria que completa su estrategia comunicativa. La campaña Re_Acciona tenía como objetivo el apostar por la filosofía corporativa de la "triple cuenta de resultados" e incidir de cara a la sociedad en que su actitud firme tiene dos caminos: el balance de resultados y el compromiso social y medioambiental.

La campaña es una estrategia destinada a reforzar la apuesta sostenible de sus actividades, y además, involucrar a la sociedad en los cambios que se están viviendo y que exigen a las empresas más responsabilidad. La estrategia de Re_Acciona abre dos interesantes frentes, por un lado muestra la necesidad imperiosa de crear proyectos para el desarrollo sostenible; y por otro convierte esta postura en un reto para el resto de la sociedad, haciendo que ésta se sienta implicada con su trascendental aportación en la construcción de ese futuro y se sienta llevada a la acción.
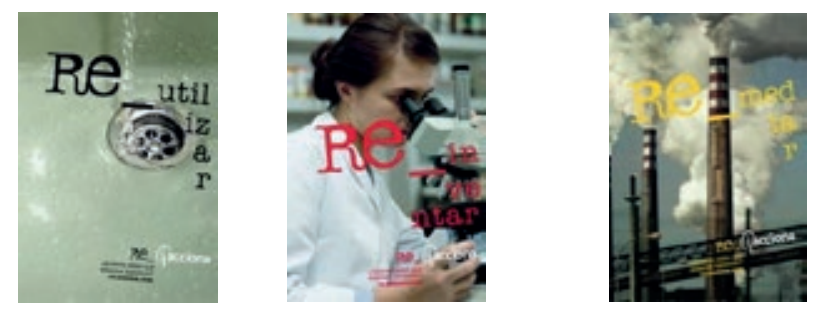

Figura 6. El Reto de Pilar

El Reto de Pilar es una acción social llevada a cabo por la empresa Buckler O,O. Pilar Cruz es una de las muchas españolas que vencen el cáncer de mama, de forma que la empresa le ha propuesto el reto de participar en todas la Carreras de la Mujer de este año y conseguir 22.000 apoyos. 
Cuando se reúnan estos 22.000 mensajes de apoyo en el buzón solidario, Buckler donará 22.000 euros en apoyo a la lucha contra el cáncer de mama, un euro por cada mujer a la que se le diagnosticará la enfermedad en España el año que viene (según datos de la ACCE). Buckler es una marca interesada en ser reconocida con valores asociados a los estilos de vida saludables.

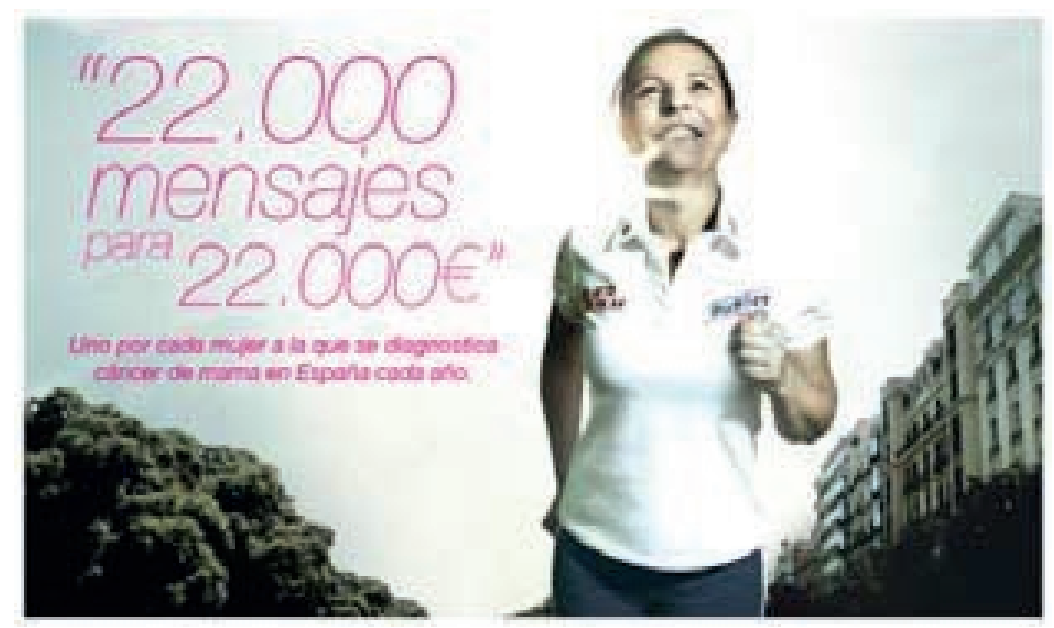

Figura 7. Starbucks

Una de las empresas consideradas como de las que mejor han construido su identidad es Starbucks. Marca asociada a valores como ecología y compromiso con la sociedad. Desde hace un año sus bebidas de café están elaboradas a partir de grano $100 \%$ procedente del comercio justo, avalado por Fairtrade.

Starbucks es uno de los mejores ejemplos de interés por las expectativas de su público. My Starbuck Idea es la aplicación en la red donde los consumidores han enviado más de seis mil ideas para mejorar la empresa. 


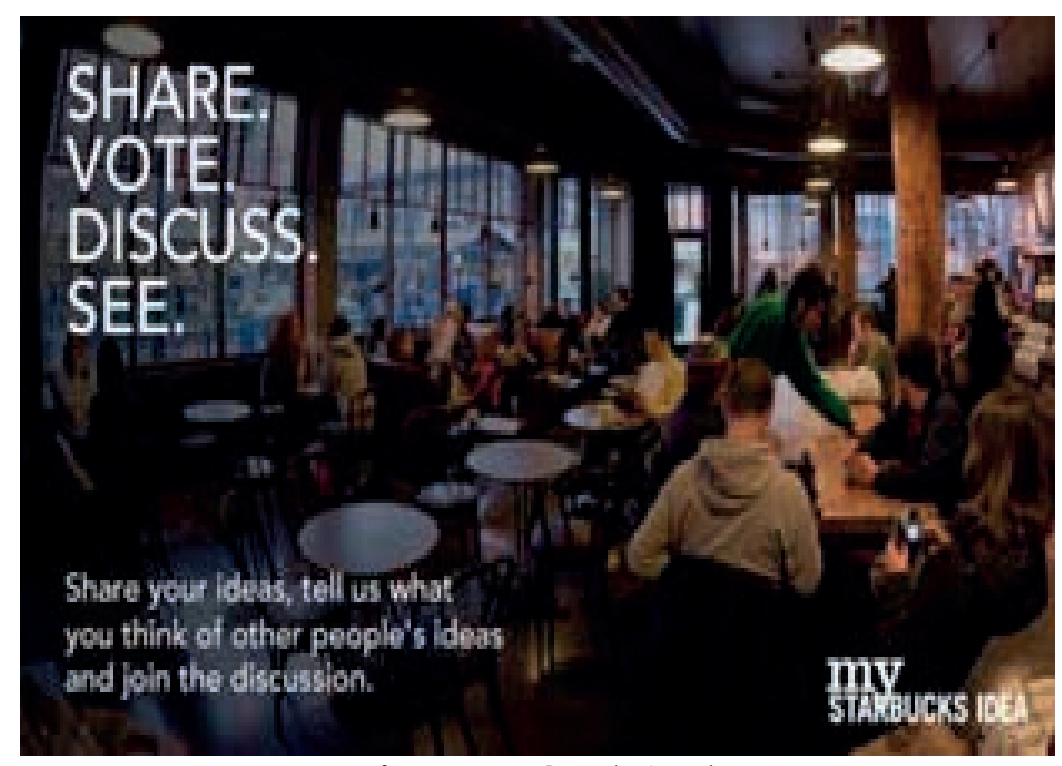

Figura 8. Good Work

Este año el festival internacional de creatividad Cannes Lions ha unido los conceptos creatividad y proyecto social. La idea se ha llamado Good Work, una propuesta destinada a unir el poder de la creatividad con la necesidad de participación en los problemas sociales. El objetivo ha sido mostrar como la creatividad, representada a nivel global en este certamen, es capaz de realizar eficaces trabajos que aborden temas serios que desafían a la sociedad. Publicidad que ayuda a llamar la atención sobre cuestiones importantes que afectan a todos, a cambiar actitudes y a motivar nuevos comportamientos. Es una forma de demostrar que desde la creatividad y desde la publicidad se pueden abordar problemas complejos y que en épocas de confusión una forma de ayudar es a través de la creatividad publicitaria.

\section{CONCLUSIONES}

La empresa de hoy ha de mantener una actitud con valores firmes si se desea que éstos sean vinculados íntegra y creíblemente a la organización. Estos valores han de estar sólidamente arraigados en su identidad corporativa, sólo así serán palanca de cambio y proyección, y escudo de protección. Por otra parte, este talante tiene fructíferos caminos para recorrer, y uno de ellos es a través de la publicidad.

La publicidad es un camino comunicativo de la empresa altamente creativo que sirve para exhibir esta apuesta firme por una identidad corporativa bien construida y consecuente con la época y circunstancias sociales con las que convive. Como se ha señalado, hace falta una fuerte postura y convicción de la empresa y de su alta dirección. Todo ello bien dirigido por un Dircom con mentalidad estratégica y creativa, que conozca todos estos conceptos teóricos y sepa llevarlos a la práctica con habilidad y desenvoltura. El Dircom sabrá manejar con destreza todos los frentes, desmenuzarlos y volverlos a reconstruir haciéndolos converger en un punto donde

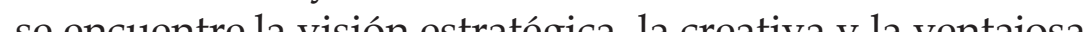


Hemos comprobado cómo cada vez más asiduamente existen campañas publicitarias que de forma original y creativa no sólo nos presentan un producto o servicio, sino que además sirven para conocer la postura de la empresa ante una cuestión social que interesa a todos. Son mensajes críticos que conducen a que el ciudadano observador reconozca unos valores vinculados a la organización y por ello la vea atractiva y estimable; y por otro, sirven a mejorar las conductas sociales. Inversión doblemente útil.

\section{REFERENCIAS}

Adam, J. M. \& Bonhomme, M. (2000). La argumentación publicitaria. Madrid: Cátedra.

Benavides, J. (1997). Lenguaje Publicitario. Hacia un estudio del lenguaje en los medios. Madrid: Editorial Síntesis.

Costa, J. (1993). Reinventar la publicidad. Reflexiones desde las ciencias sociales. Madrid: Fundesco.

Costa, J. (2001). Imagen corporativa en el siglo XXI. Buenos Aires: La crujía.

Jáuregui, R. (2009). Reputación corporativa, RSC, sostenibilidad, acción social ¿De qué hablamos? Telos, 79.

Villafañe, J. (2007). La comunicación empresarial y la gestión de los intangibles en España y Latinoamérica. Madrid: Pirámide.

Villafañe, J. (2004). Cómo valoran la reputación corporativa los CEO españoles. En El Estado de la Publicidad y el Corporate en España y Latinoamérica. Madrid:Pirámide. 


\section{Magdalena Mut Camacho}

Doctora en Comunicación empresarial e institucional por la Universitat Jaume I de Castellón y licenciada en Ciencias de la información por la Universidad Autónoma de Barcelona. Profesora del Departamento de Ciencias de la Comunicación en la titulación de Publicidad y RRPP, en la de Comunicación Audiovisual y en el Máster Oficial en Nuevas Tendencias y Procesos de Innovación en Comunicación de la Universitat Jaume I de Castelló. Profesora de máster en la Universidad Autónoma de Barcelona y en la Universidad de Valencia. Es co-directora junto a Joan Costa del Máster Internacional de Dirección y Gestión de la Comunicación para Latinoamérica.

\section{Estela Bernad Monferrer}

Licenciada en Derecho por la Universidad de Valencia y Doctora en Comunicación por la Universitat Jaume I, donde es profesora desde el inicio de esta universidad (1991). Ha pertenecido al Departamento de Derecho Privado durante los años 1991 a 2004 para posteriormente pasar al Departamento de Ciencias de la Comunicación, donde en la actualidad es miembro y profesora. Es directora del Curso de especialista Universitario UJI: "Gestión de eventos y acciones para la reputación". 